\title{
Desempenho de cultivares de alface crespa em dois ambientes de cultivo em sistema hidropônico
}

\author{
Sally F Blat ${ }^{1}$; Sérgio V Sanchez ${ }^{2}$; Jairo Augusto C de Araújo ${ }^{3}$; Denizart Bolonhezi ${ }^{1}$ \\ ${ }^{1}$ APTA Centro Leste, SAA, Av. Bandeirantes 2419, 14030-670 Ribeirão Preto-SP; ${ }^{2}$ CATI-SAA, C. Postal 444, 14010-040 Ribeirão Preto- \\ SP; ${ }^{3}$ UNESP, Rod. Paulo Donato Castellane s/n, 14884-900 Jaboticabal-SP; sally@apta.sp.gov.br
}

\section{RESUMO}

Este trabalho foi desenvolvido em Ribeirão Preto-SP, de 06/02 a 07/04 de 2006. O objetivo foi avaliar o desempenho de cinco cultivares de alface (Pira Roxa, Belíssima, Locarno, Crespona Gigante e Verônica) em dois ambientes de cultivo (casa de vegetação climatizada e não climatizada) em sistema hidropônico NFT. O delineamento experimental foi em blocos casualizados para cada ambiente com três repetições sendo cinco cultivares. Os ambientes foram comparados por meio de análise conjunta. Avaliaram-se a massa fresca e seca da parte aérea, massas fresca e seca do caule, massa fresca e seca da raiz, número de folhas maiores que $10 \mathrm{~cm}$ e número total de folhas. Não houve efeito significativo da interação cultivares e ambientes, demonstrando que as cultivares tiveram comportamento similar em ambos os ambientes.

Palavras-chave: Lactuca sativa L., cultivo sem solo, ambientes, cultivar.

\begin{abstract}
Performance of lettuce cultivars grown in two environments, in the NFT hydroponic system

This research was carried out in Ribeirão Preto, São Paulo State, Brazil, from February to April, 2006. The performance of five lettuce cultivars (Pira Roxa, Belíssima, Locarno, Crespona Gigante and Verônica) was evaluated, growing the plants in two environments (conventional and acclimatized greenhouse) in hydroponic system NFT. A randomized-block experimental design was used for each environment, with three replications and five cultivars. The environments were compared through joint analysis. Evaluations were done for fresh and dry mater of the aboveground part, stem, and roots; number of leaves larger than $10 \mathrm{~cm}$ and total number of leaves. The cultivars Crespona Gigante and Verônica were prominent with regard to green and dry mass of the aboveground part, leaves, and roots, as well as to the number of leaves larger than $10 \mathrm{~cm}$. The interaction cultivar $\mathrm{x}$ environment was not significant, demonstrating that the cultivars had similar behavior in both environments.
\end{abstract}

Keywords: Lactuca sativa L., soilless cultivation, enviroments, cultivar.

(Recebido para publicação em 17 de julho de 2009; aceito em 18 de fevereiro de 2011) (Received on July 17, 2009; accepted on February 18, 2011)

\begin{abstract}
A alface (Lactuca sativa) é a hortaliça folhosa de maior importância no Brasil com área cultivada de aproximadamente 35 mil ha. Seu cultivo é intensivo e atualmente o mercado de sementes de alface é estimado em torno de US\$ 2 milhões por ano (Costa \& Sala, 2005). O tipo predominante no Brasil é do grupo crespa, liderando $70 \%$ do mercado. As do grupo americana e lisa detêm $15 \%$ e $10 \%$, respectivamente, enquanto outras (vermelha, mimosa, romana) correspondem a 5\% do mercado (Sala \& Costa, 2005).

Nas últimas décadas têm sido desenvolvidos e adotados sistemas de cultivo protegido, principalmente o hidropônico, por viabilizar a produção durante o ano todo, facilitar o manejo da cultura, maximizar o aproveitamento dos insumos, possibilitar o controle parcial das condições ambientais adversas, além
\end{abstract}

de maior praticidade ao consumidor na limpeza do produto final. Por ser uma técnica relativamente nova no Brasil, não foi ainda adequadamente explorada em termos de pesquisa e, portanto, são poucos os relatos sobre as cultivares de alface testadas (Lopes et al., 2003).

No mercado, estão disponíveis muitas cultivares de alface, algumas já adaptadas ao cultivo protegido enquanto para outras não existem recomendações, principalmente, para cultivo hidropônico (Gualberto et al., 2009). A ausência de cultivares selecionadas ou melhoradas para o cultivo protegido em casas de vegetação tem se tornado um fator limitante ao desenvolvimento dessa modalidade de exploração em determinadas regiões (Oliveira et al., 2004).

As cultivares de alface podem diferir quanto à duração do período vegetativo, florescimento, número de folhas e massa da planta (Lêdo, 1998) sendo estes influenciados pelo fotoperíodo e principalmente pela temperatura. Temperaturas acima de $20^{\circ} \mathrm{C}$ podem causar o pendoamento precoce, fator que inutiliza a planta para o consumo. (Silva et al., 1999; Sala \& Costa, 2005). A alface é bastante sensível a condições adversas de temperatura, produzindo melhor nas épocas mais frias do ano (Oliveira et al., 2004).

Oliveira et al. (2004) verificaram que as cultivares Mimosa, Brisa, Regina, Monalisa e OGR são as mais indicadas para integrar programas de cruzamentos dirigidos, visando produzir novas cultivares destinadas ao cultivo hidropônico, mostrando-se mais divergentes e apresentando boas qualidades agronômicas, principalmente massa seca da planta.

Visando selecionar as melhores cultivares de alface dos grupos americana, 
crespa e lisa para cultivo hidropônico em condições de verão em Viçosa-MG, Sediyama et al. (2000) verificaram que no grupo das crespas as cultivares Salad Bowl e Brisa apresentaram maior número de folhas seguidas da Marisa e Verônica. Para comprimento do caule a cultivar Salad Bowl seguida da 'Verônica' e 'Brisa' apresentaram maior comprimento do caule, evidenciando menor resistência ao pendoamento. Em relação à produção de massa fresca por planta, nenhum dos grupos apresentou diferença significativa. Apesar disso, no grupo das crespas, 'Verônica' apresentou numericamente a segunda maior massa.

Quatro cultivares de alface do grupo crespa foram estudadas por Feltrim et al. (2009) em cultivo protegido em solo e em hidroponia em JaboticabalSP. As cultivares Marisa, Verônica e Vera mostraram-se mais adaptadas aos dois sistemas de cultivo, apresentando maior massa fresca da parte aérea. No cultivo de verão houve redução do acúmulo de massa fresca em cerca de $40 \%$, constituindo-se em época pouco adequada á produção de alface em Jaboticabal e demandando manejo cultural apropriado para se produzir alface em mercado competitivo.

O desempenho produtivo, adaptabilidade e estabilidade fenotípica de seis cultivares de alface do grupo crespa em três épocas de plantio no sistema hidropônico NFT foi estudado por Gualberto et al. (2009), verificando-se que das seis cultivares, 'Deyse' e 'Verônica' foram as únicas a mostrarem adaptabilidade a todos ambientes estudados para produtividade e massa fresca da parte aérea. 'Verônica' apresentou valores superiores à média geral. Todas as cultivares apresentaram instabilidade para as características de produção. Evidenciaram ainda que para alfaces do grupo crespa, há intensa variação de comportamento das cultivares em relação ao ambiente que são submetidas, demonstrando que no sistema hidropônico também é importante avaliar as diferentes cultivares disponíveis no mercado.

O objetivo deste trabalho foi avaliar o desempenho de cultivares de alface crespa em dois ambientes protegidos, casa de vegetação convencional e clima- tizada, em condições de sistema hidropônico NFT, em Ribeirão Preto-SP.

\section{MATERIAL E MÉTODOS}

O experimento foi conduzido na área experimental da APTA Centro Leste com sede em Ribeirão Preto (21 ${ }^{\circ} 10^{\prime} 42^{\prime \prime} \mathrm{S}, 47^{\circ} 48^{\prime} 24^{\prime \prime} \mathrm{W}, 545 \mathrm{~m}$ de altitude), em condições de sistema hidropônico, de 06/02 a 07/04 de 2006. No verão, a temperatura média mensal é de cerca de $33^{\circ} \mathrm{C}$ com índice pluviométrico superior a $200 \mathrm{~mm}$ mensais e umidade relativa do ar em torno de $80 \%$. As temperaturas médias na casa de vegetação climatizada foram máxima de $30,6^{\circ} \mathrm{C}$ e mínima de $20,4^{\circ} \mathrm{C}$ e na convencional, máxima de $37,0^{\circ} \mathrm{C}$ e mínima de $19,8^{\circ} \mathrm{C}$. Na convencional, observaram-se valores superiores a $40^{\circ} \mathrm{C}$ em oito dias, após o transplante das mudas de alface.

Cinco cultivares de alface do tipo crespa (Pira Roxa, Belíssima, Locarno, Crespona Gigante e Verônica) foram avaliadas em dois modelos de casas de vegetação. O tipo convencional, Hidrogood $^{\circledR}$, tinha dimensões de $8 \times 9$ $\mathrm{m}$, coberta com filme de polietileno 150 micra e tela de sombreamento lateral, e o tipo climatizada, Poly House da Van der Hoeven, tinha dimensões de 13 x 9 $\mathrm{m}$, composta por cobertura e fechamento em filme de polietileno duplo 150 micra e inflado por micro-ventilador, sistema automático de nebulização, exaustores e cortina de sombreamento $50 \%$ com malha refletora na parte externa que ficava aberta das $10 \mathrm{~h}$ às $16 \mathrm{~h}$ nos dias mais ensolarados.

Foi utilizado o sistema hidropônico NFT (técnica do fluxo laminar de nutrientes). A solução nutritiva adotada foi a proposta por Furlani et al. (1999). Os sistemas hidropônicos das duas casas de vegetação foram semelhantes, compostos por três bancadas (repetições), cada qual com sete canais de produção (bancada definitiva). Cada canal (tubos de polipropileno atóxico de $6 \mathrm{~m}$ ) possuía sistemas de reservatórios (tambores plásticos com capacidade para $50 \mathrm{~L}$ ) e bombas (1/2 HP) individualizados. Em cada bancada, os cinco canais centrais foram utilizados para cada uma das cultivares e os dois canais das extremidades serviram de bordadura.
A semeadura foi realizada em 06/02/2006 em espuma fenólica, colocadas em bancada de ferro e irrigadas até a emergência das plântulas. Em seguida essas plântulas receberam a solução nutritiva (vazão em torno de 1,0 $\mathrm{L} \mathrm{min}^{-1}$, condutividade elétrica $1,3 \mathrm{mS} \mathrm{cm}^{-1}$ e $\mathrm{pH}$ 5,5 , a 6,5 ) na bancada de crescimento, tendo espaçamentos entre plântulas de 3 $\mathrm{cm}$. Quando as plântulas tinham de 6 a 8 folhas definitivas (10/03/2006), foram transplantadas para os canais nas bancadas definitivas onde permaneceram até a colheita. Em cada bancada definitiva, o espaçamento foi de $20 \mathrm{~cm}$ entre os canais e $15 \mathrm{~cm}$ entre plantas dentro de cada canal, perfazendo um total de 22 plantas por canal ou parcela. A solução nutritiva teve vazão de 1,5 a 2,0 $\mathrm{L} \mathrm{min}^{-1}$, condutividade elétrica mantida em 1,7 $\mathrm{mS} \mathrm{cm} \mathrm{cm}^{-1}$ e $\mathrm{pH} 5,5$ a 6,5. O esquema de circulação da solução nutritiva foi comandado por um timer programado para promover a circulação de $15 \mathrm{em} 15 \mathrm{mi}$ nutos durante o dia e durante o período noturno o sistema foi desligado.

O delineamento experimental, individualizado para cada ambiente (convencional e climatizado), foi em blocos casualizados, com três repetições. Os tratamentos foram constituídos pelas cinco cultivares sendo as parcelas pelos canais de cultivo com 22 plantas (bancadas) em cada ambiente protegido.

A colheita foi realizada aos 61 dias da semeadura, quando as plantas apresentaram o máximo desenvolvimento vegetativo, antes de iniciar o pendoamento. Foram avaliados a massa fresca e seca da parte aérea, massa fresca e seca do caule, massa fresca e seca da raiz, número de folhas maiores que 10 $\mathrm{cm}$ de comprimento e número total de folhas. Para obtenção das massas secas, as partes das plantas foram colocadas em sacos de papel e em estufa com circulação de ar forçada a $65^{\circ} \mathrm{C}$ por 72 horas.

Os dados foram submetidos à análise de variância (teste F), sendo as médias comparadas pelo teste de Tukey ao nível de $5 \%$. Foi feita análise conjunta considerando os dados dos dois ambientes.

\section{RESULTADOS E DISCUSSÃO}

Não houve efeito significativo da interação cultivares e ambientes sobre as 
Tabela 1. Massas fresca e seca (g) de parte aérea (MFPA, MSPA), folhas (MFF, MSF), caule (MFC, MSC), raiz (MFR, MSR), número total de folhas e maiores que $10 \mathrm{~cm}$ de comprimento (NTF, NF 10) de cultivares de alface em dois ambientes no sistema hidropônico (fresh and dry mass of the aerial part, leaves, stem, roots; total number of leaves and number of leaves larger than $10 \mathrm{~cm}$ of lettuce cultivars grown in two environmentals the hydroponic system). Ribeirão Preto, APTA, 2006.

\begin{tabular}{lcccccccccc}
\hline Ambientes (A) & MFPA & MSPA & MFF & MSF & MFC & MSC & MFR & MSR & NTF & NF 10 \\
\hline Estufa convencional & $130,6 \mathrm{a}$ & $6,5 \mathrm{a}$ & $115,8 \mathrm{a}$ & $5,6 \mathrm{a}$ & $14,8 \mathrm{a}$ & $0,9 \mathrm{a}$ & $33,8 \mathrm{a}$ & $1,6 \mathrm{a}$ & $28,9 \mathrm{a}$ & $11,3 \mathrm{a}$ \\
Estufa climatizada & $74,5 \mathrm{~b}$ & $3,9 \mathrm{~b}$ & $61,6 \mathrm{~b}$ & $3,0 \mathrm{~b}$ & $12,9 \mathrm{a}$ & $0,9 \mathrm{a}$ & $16,9 \mathrm{~b}$ & $0,8 \mathrm{~b}$ & $21,6 \mathrm{~b}$ & $9,9 \mathrm{a}$ \\
\hline DMS (5\%) & 36,1 & 1,4 & 31,35 & 1,2 & 5,6 & 0,3 & 5,5 & 0,3 & 4,4 & 2,8 \\
\hline Cultivares (C) & & & & & & & & & & \\
\hline Belíssima & $65,6 \mathrm{~b}$ & $3,5 \mathrm{~b}$ & $57,1 \mathrm{~b}$ & $2,9 \mathrm{~b}$ & $8,5 \mathrm{~b}$ & $0,5 \mathrm{~b}$ & $16,9 \mathrm{~b}$ & $0,9 \mathrm{~b}$ & $22,3 \mathrm{a}$ & $7,9 \mathrm{~b}$ \\
Pira Roxa & $60,4 \mathrm{~b}$ & $3,9 \mathrm{~b}$ & $53,4 \mathrm{~b}$ & $3,2 \mathrm{~b}$ & $6,9 \mathrm{~b}$ & $0,6 \mathrm{~b}$ & $18,9 \mathrm{~b}$ & $0,8 \mathrm{~b}$ & $27,6 \mathrm{a}$ & $10,5 \mathrm{ab}$ \\
Locarno & $89,2 \mathrm{~b}$ & $3,9 \mathrm{~b}$ & $77,4 \mathrm{~b}$ & $3,3 \mathrm{~b}$ & $11,8 \mathrm{ab}$ & $0,7 \mathrm{~b}$ & $29,5 \mathrm{a}$ & $1,4 \mathrm{ab}$ & $22,5 \mathrm{a}$ & $8,5 \mathrm{~b}$ \\
Crespona Gigante & $179,2 \mathrm{a}$ & $8,3 \mathrm{a}$ & $161,5 \mathrm{a}$ & $7,4 \mathrm{a}$ & $17,6 \mathrm{ab}$ & $0,9 \mathrm{ab}$ & $33,4 \mathrm{a}$ & $1,8 \mathrm{a}$ & $30,2 \mathrm{a}$ & $16,4 \mathrm{a}$ \\
Verônica & $118,7 \mathrm{ab}$ & $6,4 \mathrm{ab}$ & $94,2 \mathrm{ab}$ & $4,7 \mathrm{ab}$ & $24,5 \mathrm{a}$ & $1,7 \mathrm{a}$ & $27,2 \mathrm{a}$ & $1,4 \mathrm{ab}$ & $23,8 \mathrm{a}$ & $9,7 \mathrm{~b}$ \\
\hline DMS (5\%) & 82,7 & 3,2 & 71,6 & 2,7 & 12,8 & 0,8 & 12,6 & 0,6 & 10,1 & 6,3 \\
\hline Teste F $($ AxC $)$ & $0,5^{\text {ns }}$ & $0,7^{\text {ns }}$ & $0,4^{\text {ns }}$ & $1,0^{\text {ns }}$ & $1,0^{\text {ns }}$ & $0,5^{\text {ns }}$ & $1,7^{\text {ns }}$ & $2,9^{\text {ns }}$ & $1,0^{\text {ns }}$ & $1,4^{\text {ns }}$ \\
\hline CV $(\%)$ & 45,5 & 35,3 & 45,6 & 35,3 & 51,9 & 49,6 & 28,3 & 27,7 & 22,6 & 33,7 \\
\hline
\end{tabular}

características avaliadas. Analisando-se cada fator separadamente, observou-se que as cultivares diferiram com relação a todas as características avaliadas, exceto número total de folhas. Da mesma forma, o ambiente de cultivo só não influenciou as massas fresca e seca de caule e número de folhas maiores que 10 cm de comprimento (Tabela 1).

Nesse experimento, pode-se verificar que o cultivo da alface crespa em casa de vegetação convencional foi mais adequado do que na climatizada, uma vez que as massas frescas e secas da parte aérea, folhas e raízes e o número total de folhas foram maiores nesse ambiente (Tabela 1). Esse fato pode ter ocorrido pela maior transpiração das plantas na casa de vegetação convencional em virtude da maior incidência da radiação solar, traduzindo em fotossíntese e consequentemente maior produção de biomassa. Na casa de vegetação climatizada o filme de polietileno duplo faz com que a radiação solar seja menor. Esses resultados são coerentes com os obtidos por Verdade et al. (2003), os quais obtiveram em seu experimento com alface em época de verão, massa fresca média de folhas de $133 \mathrm{~g} /$ planta em casa de vegetação convencional e $112 \mathrm{~g} /$ planta em casa de vegetação climatizada.

As cultivares que mais se destacaram em massa fresca e seca da parte aérea, indicando uma produção dentro dos padrões comerciais para a espécie, foram Crespona Gigant e Verônica (Tabela 1). Gualberto et al. (2009) também verificaram em seus experimentos que a cultivar Verônica destacou-se entre as demais apresentando uma das maiores massas frescas da parte aérea, classificando-a ainda como a de maior adaptabilidade geral nos ambientes de cultivo. Já, nos experimentos realizados por Schmidt et al. (2001), a cultivar Verônica apresentou as menores massas frescas e secas, que foram de 99,4 $\mathrm{g} \mathrm{e}$ 4,4 g, respectivamente.

Analisando-se separadamente os componentes da parte aérea, quanto à massa fresca e seca de folhas, também as cultivares Crespona Gigante e Verônica apresentaram os maiores desenvolvimentos, sendo que apenas a 'Crespona Gigante' diferiu estatisticamente das cultivares Belíssima, Pira Roxa e Locarno (Tabela 1). Resultados semelhantes para a cultivar Verônica foram obtidos por Oliveira et al. (2003).

Em relação às massas fresca e seca do caule, a cultivar Verônica apresentou as maiores massas (Tabela 1) diferindo das cultivares Belíssima e Pira Roxa. Esses resultados são concordantes com os obtidos por Sediyama et al. (2000) e Oliveira et al. (2003), nos quais trabalhos a cultivar Verônica foi superior às demais estudadas. No caso do caule, esse maior valor torna-se um aspecto negativo, sugerindo que a cultivar tem maior suscetibilidade ao pendoamento. Nesse aspecto as cultivares que apresentaram maior resistência ao pendoamento foram principalmente Belíssima e Pira Roxa.

Apesar de as cultivares terem diferido em massa de folhas, o número total de folhas foi estatisticamente semelhante para todas elas (Tabela 1). Pode-se inferir que Crespona Gigante tem folhas maiores que Belíssima, Verônica e Locarno. Esse fato pode ser confirmado pelo número de folhas maiores que $10 \mathrm{~cm}$, sendo na cultivar Crespona Gigante significativamente maior que para as demais. 'Verônica' apresentou quantidade menor de folhas $>10 \mathrm{~cm}$ que aquela obtida com a mesma cultivar no experimento de Feltrim et al. (2009). O tamanho exagerado de folhas muitas vezes é indesejável pela dificuldade de embalagem pelos danos causados às folhas (Sediyama et al. 2000).

As cultivares Crespona Gigante, Verônica e Locarno tiveram as maiores massas frescas e seca de raízes (Tabela 1). Oliveira et al. (2003), avaliando a cultivar Verônica obtiveram umas das maiores massas frescas de raízes em relação às demais cultivares avaliadas. Para massa seca, os autores não observaram diferenças significativas diferindo dos resultados do presente experimento.

As médias de massa fresca e seca da parte aérea observadas neste experi- 
mento estão abaixo das médias obtidas em experimentos desse mesmo tipo verificadas por outros autores, tal como Schmidt et al. (2001). Provavelmente, seja devido às altas temperaturas nesses locais prejudicando o crescimento da cultura da alface. Segundo Feltrim et al. (2009) comparando-se as melhores épocas do ano para o plantio, verificase que as plantas de alface acumulam menos massa seca na parte aérea nas épocas mais quentes, principalmente no plantio de verão devido ao estresse térmico por altas temperaturas.

Se a escolha da melhor cultivar for analisada apenas levando-se em consideração os resultados de massa seca de parte aérea e raiz, pode-se afirmar que Crespona Gigante e Verônica foram as de melhor desempenho. Porém, nas condições ambientais de Ribeirão Preto, onde o calor é excessivo e especificamente da época de realização do experimento, uma característica importante é a resistência ao pendoamento; nesse aspecto, as cultivares Pira Roxa e Belíssima destacaram-se para essa característica.

\section{REFERÊNCIAS}

COSTA CP; SALA FC. 2005. A evolução da alfacicultura brasileira. Horticultura Brasileira 23 (Artigo de capa).

FELTRIM AL; CECILIO FILHO AB; REZENDE BLA; BRANCO RBF. 2009. Produção de alface-crespa em solo e em hidroponia, no inverno e verão, em Jaboticabal-SP. Cientifica 37: 9-15.

FURLANI PR; SILVEIRA LCP; BOLONHEZI D; FAQUIN V. 1999. Cultivo hidropônico de plantas. Campinas: Instituto Agronômico. $52 \mathrm{p}$.

GUALBERTOR; OLIVEIRAPSR; GUIMARÃES AM. 2009. Adaptabilidade e estabilidade fenotípica de cultivares de alface do grupo crespa, em cultivo hidropônico. Horticultura Brasileira 27: 7-11.

LÊDO FJS. 1998. Diversidade genética e análise dialélica da eficiência nutricional para nitrogênio em alface (Lactuca sativa $\mathrm{L}$.). Viçosa: UFV. 87p. (Tese doutorado).

LOPES MC; FREIER M; MATTE JD; GARTNER M; FRANZENER G; CASIMIRO ELN; SEVIGNANI A. 2003. Acúmulo de nutrientes por cultivares de alface em cultivo hidropônico no inverno. Horticultura Brasileira 21: 211215.

OLIVEIRA CEP; LUZ JMQ; MARTINS ST; DINIZ KA; CARLIS GC; SILVA AM. 2003.
Produção de cultivares de alface em sistema hidropônico com perfis parciais ou totalmente pintados de branco. In: CONGRESSO BRASILEIRO DE OLERICULTURA, 43. Resumos... Recife: ABH (CD-ROM).

OLIVEIRAACB; SEDIYAMA MAN; PEDROSA MW; GARCIA NC; GARCIA SLR. 2004. Divergência genética e descarte de variáveis em alface cultivada sob sistema hidropônico. Acta Scientiarum Agronomy 26: 211-217.

SALAFC; COSTA CP. 2005. 'Pira Roxa': Cultivar de alface crespa de cor vermelha intensa. Horticultura Brasileira 23: 158-159.

SCHMIDT D; SANTOS OS; BONNECARRÈRE RAG; MARIANI OA; MANFRON PA. 2001. Desempenho de soluções nutritivas e cultivares de alface em hidroponia. Horticultura Brasileira 19: 122-126.

SEDIYAMA MAN; PEDROSA MW; GARCIA NCP; GARCIA SRL. 2000. Seleção de cultivares de alface para cultivo hidropônico. Horticultura Brasileira 18: 244-245.

SILVA EC; LEAL NR; MALUF WR. 1999. Avaliação de cultivares de alface sob altas temperaturas em cultivo protegido em três épocas de plantio na região Norte-fluminense. Ciências Agrotécnicas 23: 491-499.

VERDADE SB; BOLONHEZI D; FERREIRA WM; MACHADO NETO JG 2003. Consumo de água de alface hidropônica cultivada em estufa convencional e climatizada. In: XXIX CONGRESSO BRASILEIRO DE CIÊNCIA DO SOLO, Anais... Ribeirão Preto (CDROM). 